\title{
A MATHEMATICAL MODEL OF GALVANIC CORROSION UNDER THE CONDITIONS OF A THIN ELECTROLYTE FILM
}

\author{
VÍT JenÍČEK, LindA DiBLÍKOvÁ \\ Výzkumný a zkušební letecký ústav, a.s., Beranových 130, 19905 Praha - Letñany, Czech Republic \\ correspondence: pazderova@vzlu.cz
}

\begin{abstract}
A mathematical model of galvanic corrosion under the conditions of a thin electrolyte film was used to evaluate atmospheric corrosion. Experimentally determined weight loss values were used to validate the modelled results. The time dependence of the corrosion degradation was included in the model using polarization curves of the corroded materials. The difference between the modelled results and the experimental results was $20 \%$, taking the experimental error into account.
\end{abstract}

KEYWORDS: atmospheric corrosion, galvanic corrosion, modelling, weight loss.

\section{INTRODUCTION}

Atmospheric corrosion is the type of corrosion that causes the greatest economic losses in our inland conditions. Great efforts are being made to model atmospheric corrosion mathematically, because these models can be helpful in various fields of technology. In general, the main problem in corrosion modelling is the complexity of the corrosion process. A sophisticated mathematical model and a broad variety of input parameters are required in order to ensure usable and realistic behaviour of the model. Atmospheric corrosion typically takes place in a thin electrolyte layer (TEL) of adsorbed moisture. Chemical reactions taking place in the system need to be resolved. The transport of the reactants and products and the kinetics of the corrosion and depolarization reactions must be known. In addition, changes in electrolyte composition, dissolution of the anode and any settling of the corrosion products influence the polarization of the anode and the cathode. The electrical current flow in the electrolyte must also be determined in order to cover the electrochemical nature of the corrosion reactions.

Mathematical modelling is relatively well applicable to galvanic corrosion, which occurs when two electrochemically different materials are in contact. Early models solved galvanic corrosion over special geometrical shapes analytically [1, 2]. Later, finite element methods (FEM) were introduced to solve general geometries. A widely-used approach solves the Laplace equation for the electric potential in the volume of the electrolyte. The polarization curves of the materials represent the boundary conditions $3-6$. When atmospheric corrosion is solved, it is necessary to take into account that the polarization curves measured in a TEL are different from the curves measured in a bulk electrolyte [7+9].

This paper presents a relatively simple and straightforward way to model the galvanic contribution to atmospheric corrosion. This contribution is important in the vicinity of the interfaces of different materials in any structure. In these locations, it can cause significant problems, especially when mutual influences of more than two interfaces occur and a table of the corrosion of dissimilar metals does not provide reliable information.

In this work, galvanic corrosion of bolt joints exposed to atmospheric conditions is evaluated by computational modelling and by experimental tests. The aim of the work was to find a suitable way of validating the modelled results from a qualitative point of view and also from a quantitative point of view.

\section{MAtherials AND METHOdS}

\subsection{Bolt JOINTS}

Three types of galvanic connections, represented by a bolt joint consisting of a bolt, a nut and a washer, were used as samples. The material composition of the samples is stated in Table 1 .

The bolts and the washers were made of the same metal, which had higher corrosion potential than the metal of the nuts. Galvanic corrosion therefore took place on the nut in each bolt joint. In other words, the nuts acted as anodes, and the bolts and washers became cathodes.

In addition, it was necessary to separate galvanic corrosion from other types of corrosion that might occur on bolt joints in atmospheric condition, e.g. uniform corrosion and crevice corrosion. Since all types of corrosion except galvanic corrosion occur when the same metals are connected, two reference samples were also subjected to the experiments. One reference sample was a bolt joint made completely of mild steel, and the second reference sample was made of galvanized steel. In this way, the influence of all types of non-galvanic corrosion could be determined for mild steel and for galvanized steel.

\subsection{WEATHERING TEST}

The bolt joints were freely exposed to the atmosphere for a period of five months, June 1st to 


\begin{tabular}{llll}
\hline Bolt joint & Bolt & Washer & Nut \\
\hline 1 & stainless steel & stainless steel & mild steel \\
2 & stainless steel & stainless steel & galvanized steel \\
3 & mild steel & mild steel & galvanized steel \\
\hline
\end{tabular}

TABLE 1. Materials in the bolt joints

October 31st, 2014. A stand with the samples was located at Výzkumný a zkušební letecký ústav, a.s. in Prague - Letňany. Ten sets of each combination of materials were exposed, i.e. fifty bolt joints in total.

A gravimetric method was used for an experimental evaluation of the extent of galvanic corrosion. Each bolt, nut and washer was weighed on an analytical scale (to four decimal places, in grams) before exposure. After exposure, the corrosion products were removed in accordance with ISO 8407:2009, using interval pickling, and the weight loss of each bolt, nut and washer was determined. The average weight loss of the nuts in three types of bolt joints, and also in two types of reference bolt joints, was calculated. To obtain the weight loss of the nuts caused by galvanic corrosion, the values for the reference samples were subtracted from the values for the modelled samples.

\subsection{MODELLING}

BEASY Corrosion Manager (BEASY CM) software (CM BEASY Ltd., UK) was used for modelling in this work. This software is based on a simplification of the galvanic corrosion process due to the presence of TEL [10]. The scheme of the process is shown in Figure 1 .

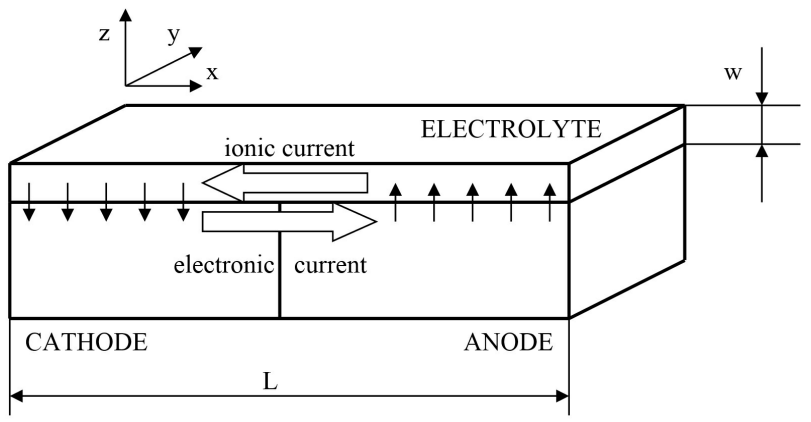

FiguRE 1. Galvanic corrosion under a TEL, $w \ll L$

The solved equation is the charge conservation equation under steady state in the volume of the electrolyte

$$
\nabla \vec{j}=0
$$

where $\vec{j}$ is the current density given by $\vec{j}=-\sigma \nabla V_{e}(X)$, $\sigma$ is the electrolyte conductivity, and $V_{e}(X)$ is the electric potential in the volume of the electrolyte at point $X \in \mathbb{R}^{3}$. The boundary conditions for the surface of the anode and the cathode are described by the corresponding polarization curves for the material of the anode and for the material of the cathode.
In the software, the assumption about TEL is treated mathematically. If the thickness of the electrolyte $w$ is much smaller than the characteristic dimension of the solved problem $L$ (see Figure 1), the electrical potential in the electrolyte can be considered as constant in the direction perpendicular to the surface of the electrode ( $z$ direction). This does not allow us to find the solution for the charge conservation equation in the whole volume of the electrolyte. The solution must be found in the two directions parallel with the surface ( $x$ and $y$ direction). In the $z$ direction, the $z$ component of current density $j_{z}$ can be directly integrated along the thickness $w$. This assumption about TEL lowers the dimensionality of the problem from 3D to 2D. The effect of the charge exchange between the electrode and the electrolyte is presented as a source term, rather than as a boundary condition.

In the simulation software used here, the corrosion behaviour of the modelled materials is described by their polarization curves. Polarization curve data must therefore be included in the input data. A similar approach can be found in other corrosion softwares, e.g. [11. For a realistic model of a real situation, the curves are measured under conditions similar to those prevailing during exposure. For atmospheric corrosion, this means measuring the polarization curves in the TEL of rainwater. The procedure for potentiodynamic measurements is described in Section 2.4. The polarization curves have to be measured in a sufficiently broad potential window to cover all potentials possibly occurring in the modelled situation. Subsequently, the curves can characterize the corrosion behaviour of a given material under activation control (in the Tafel region), and also under diffusion control (outside the Tafel region).

Other input parameters of the mathematical model are the electrical conductivity of the electrolyte and the thickness of TEL covering the modelled structure during exposure. The first approximation of TEL and its occurrence during exposure can be made according to the ISO 9223:2012 standard as the time of wetness. However, this approach has some limitations 12. In addition, the software that is used can solve galvanic corrosion even in very thin layers of adsorbed moisture. The electrolyte was represented by artificial rainwater, with conductivity of $0.0014 \mathrm{~S} \mathrm{~m}^{-1}$ at $25^{\circ} \mathrm{C}(\mathrm{pH}$ meter/conductometer MODEL 250, Denver Instrument, USA; measured $\mathrm{pH}=6.6$ ). This value was recalculated to the average temperature during exposure of $15.7^{\circ} \mathrm{C}\left(0.0011 \mathrm{~S} \mathrm{~m}^{-1}\right)$. The thickness of the TEL 
was determined to be $30 \mu \mathrm{m}$, in accordance with the average value of the relative humidity $(\mathrm{RH})$ during exposure [13], which was $73.1 \%$. For a rainy period (the duration of the rain and the time when precipitation water is flowing off the bolt joints), another mathematical model was calculated with TEL $0.2 \mathrm{~mm}$ in thickness and $0.6 \mathrm{~mm}$ in thickness on areas where the water can rise due to capillary action. The duration of the rainy period was estimated to be 6.4 day $/$ month, on the basis of the amount of rainfall $74.8 \mathrm{~mm} / \mathrm{month}$ in the area. Climatic data were freely available on the web of the Czech Hydrometeorological Institute (WwW.chmu.cz).

The output data of the software were the distribution of the weight loss values over the surface of the bolted joints and the total corrosion current for the surface of the nut, which was used to calculate the weight loss of the nut by means of Faraday's law

$$
W L=\frac{E W \times I \times t}{F},
$$

where $W L[\mathrm{~g}]$ is the weight loss caused by galvanic corrosion, $E W\left[\mathrm{~g} \mathrm{~mol}^{-1}\right]$ is the equivalent weight of the material [14], $I[\mathrm{~A}]$ is the modelled corrosion current, $t[\mathrm{~s}]$ is the time of exposure, and $F=96485 \mathrm{C} \mathrm{mol}^{-1}$ is the Faraday constant.

To obtain the weight loss value for each nut for the whole period of exposure, it was necessary to add together the weight loss values calculated for the dry period and for the rainy period.

\subsection{Polarization Curves}

Polarization curve measurements were performed in an electrochemical cell specially designed for corrosion tests under TEL, see Figure 2

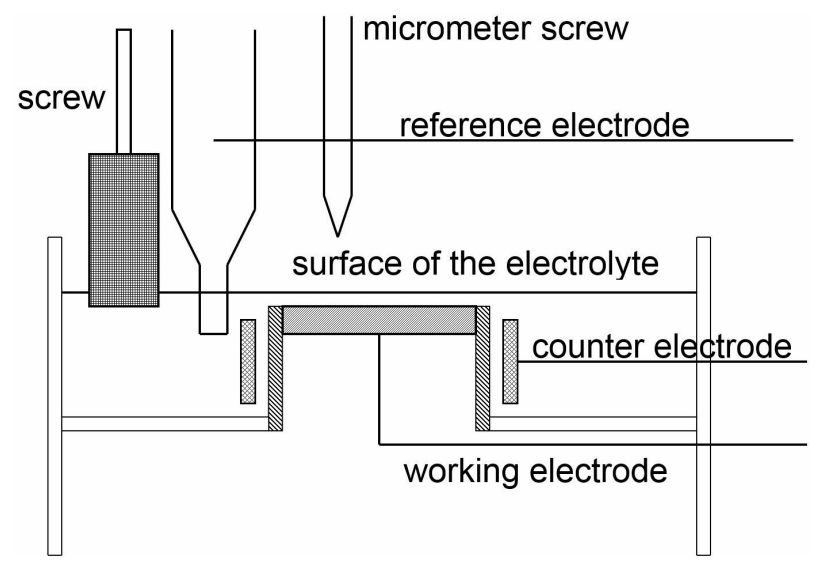

FiguRE 2. Scheme of an electrochemical cell for TEL measurements

A standard three-electrode system was used. Metal coupons (20 mm in diameter) made of mild steel, stainless steel and galvanized steel were used as the working electrode, a strip of expanded metal (stainless steel) was used as the counter electrode, and a saturated $\mathrm{Ag} / \mathrm{AgCl}$ electrode served as the reference electrode. The electrodes were connected to a Voltalab PGZ
100 potentiostat, controlled by the Voltamaster 4 programme (Radiometer analytical SAS, France). First, OCP was measured for $600 \mathrm{~s}$. Then potentiodynamic polarization curve measurements were carried out separately for the anodic and cathodic branches. Measurements of the anodic branch of the polarization curves were initiated at a cathodic potential of $-30 \mathrm{mV}$ vs. OCP, and were terminated at an anodic potential of $300 \mathrm{mV}$ vs. the reference electrode potential. For the cathodic branch of the curves, the applied voltage went from an anodic potential of $30 \mathrm{mV}$ vs. OCP to a cathodic potential of $-1200 \mathrm{mV}$ vs. the reference electrode potential for mild steel and stainless steel, and $-1300 \mathrm{mV}$ vs. the reference electrode potential for galvanized steel. The scan rate was $1 \mathrm{mV} \mathrm{s}^{-1}$. Each branch of the curve was measured three times, and then the average potential and the current values were calculated to obtain average anodic and cathodic branches. The resulting branches were joined together at the point with coordinates $\left[E_{\mathrm{corr}}^{\mathrm{av}} ; j^{\mathrm{av}}\right]$, where $E_{\mathrm{corr}}^{\mathrm{av}}$ is the average corrosion potential calculated from the corrosion potential of the anodic and cathodic branches and $j^{\text {av }}$ is $0 \mathrm{~mA} \mathrm{~cm}^{-2}$. The reproducibility of the measurements expressed as the standard deviation was $18 \mathrm{mV}$ vs. $\mathrm{Ag} / \mathrm{AgCl}$ sat. for the $E_{\text {corr }}$ values. The standard deviation of the $j_{\text {corr }}$ values did not exceed $35 \%$ of the average value.

The curves were measured for two types of coupons to simulate the time dependence of corrosion degradation, the modelling of which is not supported by the software functions. The first type was mechanically polished with fine abrasive paste, degreased with acetone and dried under an air stream prior to each potentiodynamic experiment. The second type was used as the working electrode after being subjected to the weathering test, together with the bolt joints, for a period of 5 months.

Artificial rain water was used as an electrolyte. The solution was prepared by modifying the chemical composition of demineralised water according to the composition of rainwater collected on the premises of Výzkumný a zkušební letecký ústav, a.s. In this way, the deposition rate of atmospheric pollutants, especially $\mathrm{Cl}^{-}$and $\mathrm{SO}_{2}$, was introduced into the mathematical model. The composition is given in Table 2

\begin{tabular}{cc}
\hline Chemicals & Concentration $\left[\mathrm{mgl}^{-1}\right]$ \\
\hline $\mathrm{NaF}_{2}$ & 0.05 \\
$\mathrm{KNO}_{3}$ & 1.3 \\
$\mathrm{Na}_{2} \mathrm{SO}_{4} \cdot 10 \mathrm{H}_{2} \mathrm{O}$ & 1.6 \\
$\mathrm{~K}_{2} \mathrm{SO}_{4}$ & 0.3 \\
$\mathrm{MgSO}_{4} \cdot 7 \mathrm{H}_{2} \mathrm{O}$ & 2.0 \\
$\mathrm{CaCl}_{2}$ & 0.9 \\
$\mathrm{CaSO}_{4} \cdot 2 \mathrm{H}_{2} \mathrm{O}$ & 0.9 \\
$\left(\mathrm{NH}_{4}\right)_{2} \mathrm{SO}_{4}$ & 0.8 \\
\hline
\end{tabular}

TABLE 2. Chemical composition of the artificial rain water 


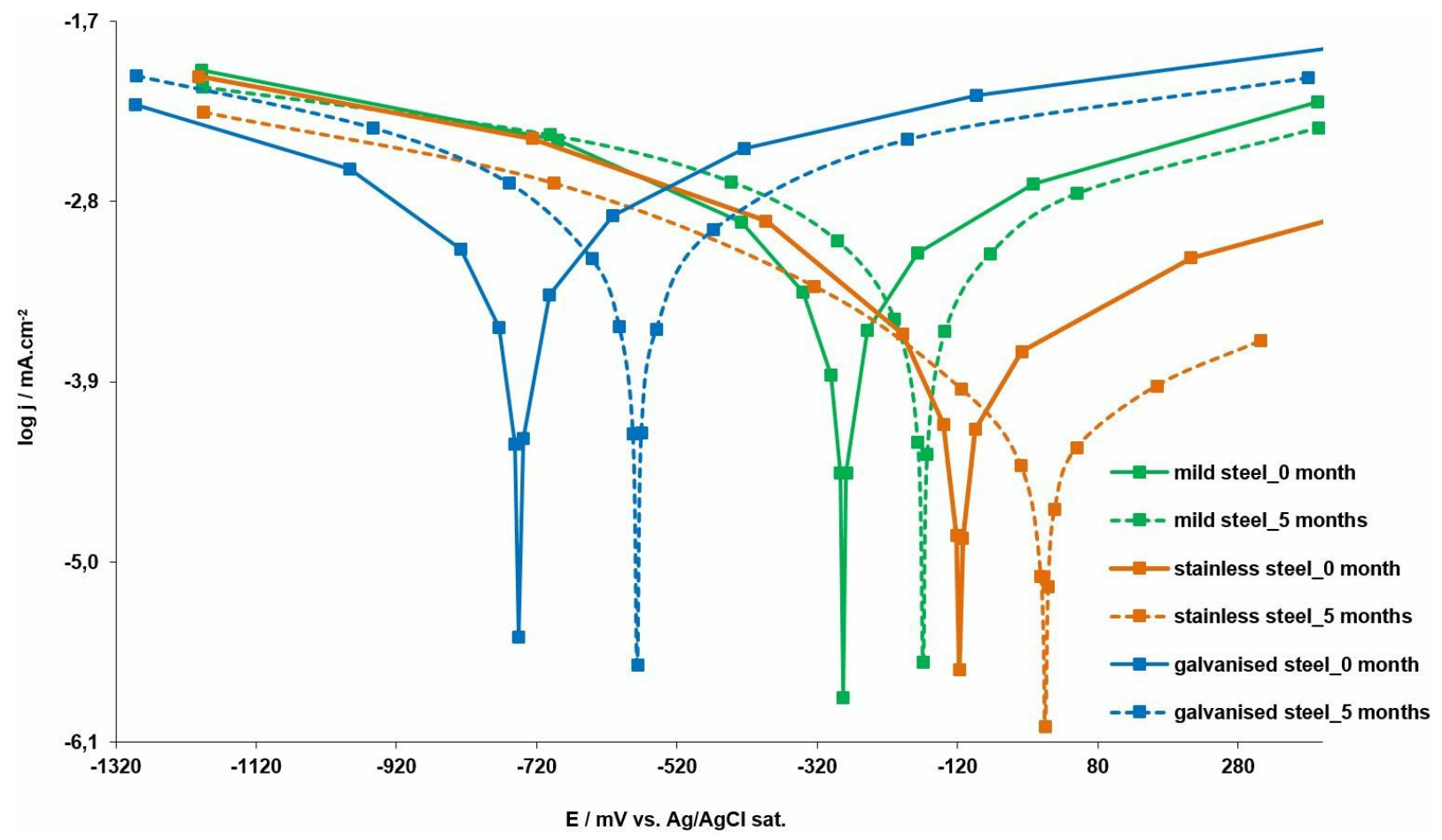

Figure 3. Polarization curves of mild, stainless and galvanized steel measured in a layer of artificial rainwater $0.5 \mathrm{~mm}$ in thickness; samples before exposure (full line) and after 5 months of exposure (dashed line)

\begin{tabular}{cccc}
\hline Bolt joint & $\begin{array}{c}\text { Total } \\
\text { weight loss }\end{array}$ & $\begin{array}{c}\text { Reference sample } \\
\text { weight loss }\end{array}$ & $\begin{array}{c}\text { Galvanic corrosion } \\
\text { weight loss }\end{array}$ \\
\hline 1 & $0.123( \pm 0.010)$ & $0.109( \pm 0.009)$ & $0.014( \pm 0.019)$ \\
2 & $0.015( \pm 0.001)$ & $0.001( \pm 0.0004)$ & $0.014( \pm 0.001)$ \\
3 & $0.019( \pm 0.003)$ & $0.001( \pm 0.0004)$ & $0.018( \pm 0.003)$ \\
\hline
\end{tabular}

TABLE 3. Experimental weight loss values for nuts in $[\mathrm{g}]$; standard deviations are added

\section{RESUlts AND DisCUSSION}

\subsection{Polarization CuRves}

Raw polarization data must be adapted according to the requirements of the software in order to lower the computational burden. Ten to twelve points specified by coordinates $E[\mathrm{~V}]$ and $j\left[\mathrm{~mA} \mathrm{~cm}^{-2}\right]$ were therefore chosen to reproduce the main features of the recorded polarization curves, see Figure 3 .

\subsection{EXPERIMENTAL RESUlTS AND MODELLING RESULTS}

The values for the experimentally determined weight loss, stated in Table 3, show that the highest total weight loss was obtained for the mild steel nuts. The corrosion of the galvanized nuts was significantly reduced due to the effect of zinc corrosion products. The contribution of galvanic corrosion to the total weight loss was almost the same for all nuts; only the nut in bolt joint 3 was slightly more affected. The photograph in Figure 4 illustrates corroded bolt joint 3. A comparison between bolt joint 3 and its model, illustrated in the same figure, shows that there is a corresponding extent of the two galvanic corrosion attacks. The attack occurred at the interface between the washer and the nut, and between the nut and the bolt. The other corrosion symptoms correspond to uniform corrosion products and secondary corrosion products.

Bolt joint 3 after exposure, together with the modelled distribution of the corrosion rate during the rainy period, are shown in Figure 4

Table 4 and Table 5 compare the output data of the SW for the materials before and after exposure. It is obvious that the corrosion damage was modelled to be equal for the dry period and the rainy period in both cases. There is also no significant difference between the resulting weight loss values for galvanic corrosion which would reflect the time dependence of the corrosion degradation. This is documented by the models in Figure 5 .

For a comparison of the experimental and the mathematically modelled weight loss values caused by atmospheric corrosion, the correspondence between the results falls within the interval of $50 \%$ for galvanized steel and for modelling using the polarization curves of new materials. The modelled results are almost within the experimentally determined weight loss intervals, taking into account the experimental error. 

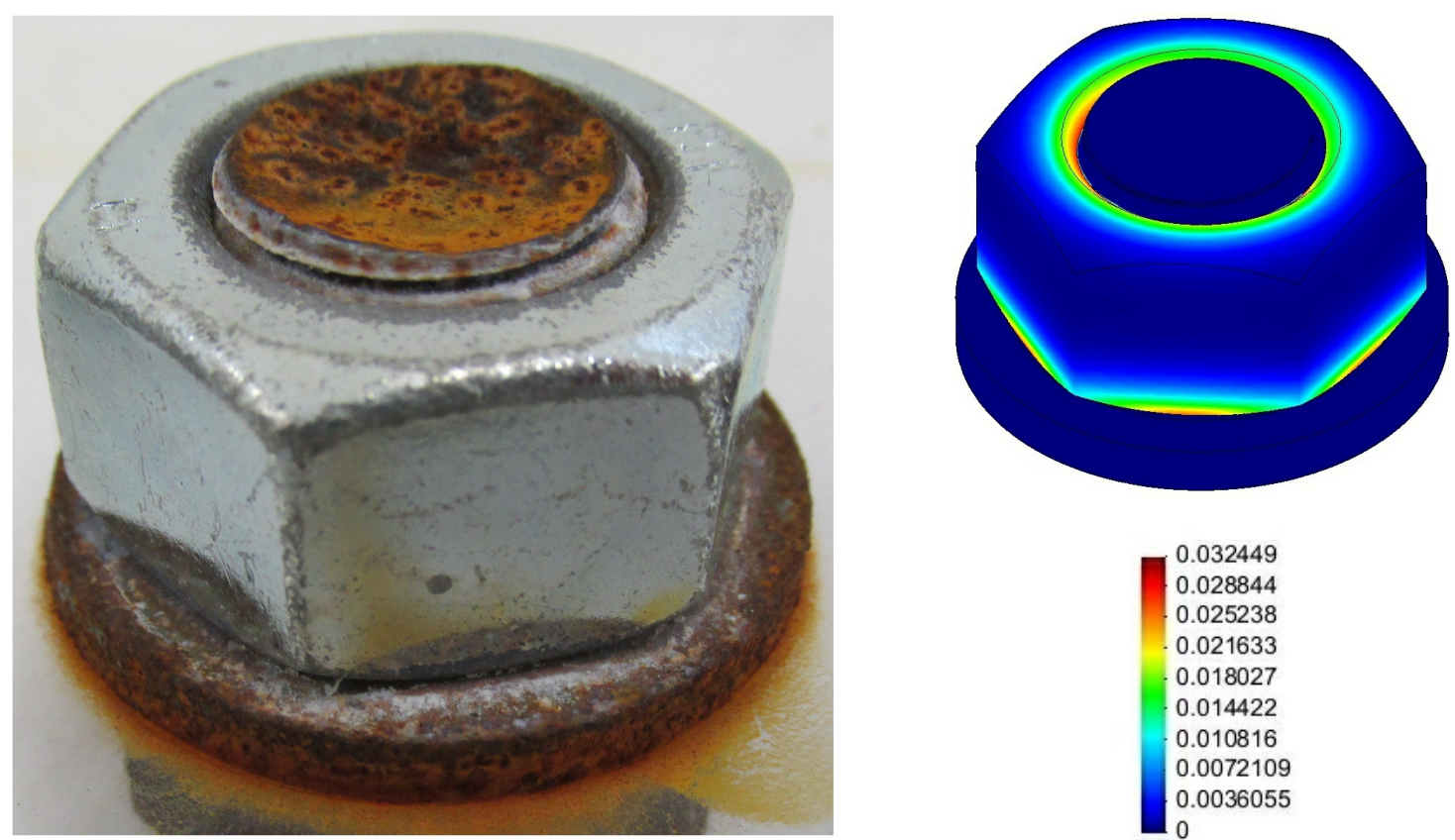

Figure 4. Bolt joint 3 after exposure, and the modelled distribution of the corrosion rate [mm/year] during the rainy period

\begin{tabular}{cccccc}
\hline Bolt joint & $\begin{array}{c}\text { Corr. current } \\
\text { dry period }\end{array}$ & $\begin{array}{c}\text { Weight loss } \\
\text { dry period }\end{array}$ & $\begin{array}{c}\text { Corr. current } \\
\text { rainy period }\end{array}$ & $\begin{array}{c}\text { Weight loss } \\
\text { rainy period }\end{array}$ & $\begin{array}{c}\text { Galvanic corr. } \\
\text { weight loss }\end{array}$ \\
\hline 1 & $3.787 \times 10^{-7}$ & 0.001 & $1.363 \times 10^{-6}$ & 0.001 & 0.002 \\
2 & $1.684 \times 10^{-6}$ & 0.006 & $6.364 \times 10^{-6}$ & 0.006 & 0.012 \\
3 & $1.502 \times 10^{-6}$ & 0.005 & $5.849 \times 10^{-6}$ & 0.005 & 0.010 \\
\hline
\end{tabular}

TABLE 4. Modelled corrosion current and weight loss values for nuts - materials before exposure; corrosion current in $[\mathrm{A}]$ a weight loss in $[\mathrm{g}]$

\begin{tabular}{cccccc}
\hline Bolt joint & $\begin{array}{c}\text { Corr. current } \\
\text { dry period }\end{array}$ & $\begin{array}{c}\text { Weight loss } \\
\text { dry period }\end{array}$ & $\begin{array}{c}\text { Corr. current } \\
\text { rainy period }\end{array}$ & $\begin{array}{c}\text { Weight loss } \\
\text { rainy period }\end{array}$ & $\begin{array}{c}\text { Galvanic corr. } \\
\text { weight loss }\end{array}$ \\
\hline 1 & $2.776 \times 10^{-7}$ & 0.001 & $8.356 \times 10^{-7}$ & 0.001 & 0.002 \\
2 & $1.065 \times 10^{-6}$ & 0.004 & $3.674 \times 10^{-6}$ & 0.003 & 0.007 \\
3 & $1.266 \times 10^{-6}$ & 0.005 & $4.878 \times 10^{-6}$ & 0.005 & 0.010 \\
\hline
\end{tabular}

TABLE 5. Modelled corrosion current and weight loss values for nuts - materials after exposure; corrosion current in $[\mathrm{A}]$ a weight loss in $[\mathrm{g}]$

The discrepancy of an order of magnitude between the modelled result and the experimental result for the mild steel nut may have been caused by the experiment, where large numbers of total weight loss values and reference sample weight loss values were subtracted. However, the modelled weight loss value complies with the experimental value when the experimental error is taken into account.

The use of polarization curves of the materials after exposure did not provide more precise modelling results in order to approximate them to the experimental weight loss values. The corrosion reaches a steady state after long-term exposure. The input data for the materials after exposure did not take into account the initial state of corrosion of the exposed bolt joints. For this reason, it should be beneficial to include the time dependence when modelling long-term corrosion, because steady state corrosion represents a substantial period of the whole time of exposure in this case. We assume that more precise agreement between modelling and experiment could be reached under these conditions.

\section{Conclusions}

A comparison between modelling results and experimental results has proved that the modelling software introduced here can be used for evaluating the contribution of galvanic corrosion to the total atmospheric corrosion of different materials that are galvanically coupled. Although not all modelled weight loss val- 


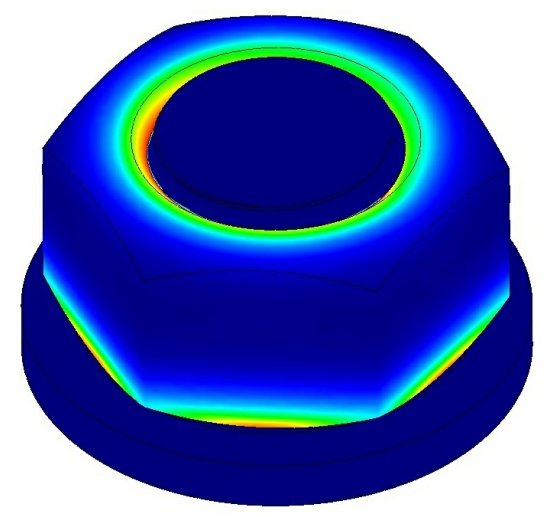

(a) before exposure

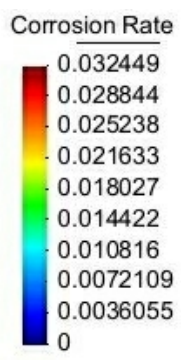

Figure 5. Modelled distribution of the corrosion rate [mm/year] on bolt joint 3 during the rainy period using the polarization curves

ues fell within the experimental values, including the experimental error, the correspondence is close. The mismatch is never greater than $20 \%$.

The use of modelling to evaluate the influence of time is less elementary. The polarization curves of materials after exposure as input data modify the modelling results, but they should be used only for modelling long-term exposures. The time limits for utilizing the polarization curves of materials after exposure need to be investigated. An experiment with exposition for a period of one year is currently in progress at Výzkumný a zkušební letecký ústav, a.s.

\section{ACKNOWLEDGEMENTS}

This work was carried out with support from the Ministry of Industry and Trade of the Czech Republic for the longterm conceptual development of a research organization.

\section{REFERENCES}

[1] J. Waber, B. Fagan. Mathematical studies on galvanic corrosion IV. influence of electrolyte thickness on the potential and current distributions over coplanar electrodes using polarization parameters. J Electrochem Soc 103(1):64-72, 1956.

[2] G.-L. Song. Potential and current distributions of one-dimensional galvanic corrosion systems. Corrosion Science 52(2):455-480, 2010. DOI:10.1016/j.corsci.2009.10.003.

[3] F. Varela, Y. Kurata, N. Sanada. The influence of temperature on the galvanic corrosion of a cast iron-stainless steel couple (prediction by boundary element method). Corrosion Science 39(4):775-788, 1997. DOI:10.1016/S0010-938X(97)89341-9.

[4] N. Murera, R. Oltraa, B. Vuillemina, O. Néelc. Numerical modelling of the galvanic coupling in aluminium alloys: A discussion on the application of local probe techniques. Corrosion Science 52(1):130-139, 2010. DOI:10.1016/j.corsci.2009.08.051

[5] K. B. Deshpande. Effect of aluminium spacer on galvanic corrosion between magnesium and mild steel using numerical model and SVET experiments.

Corrosion Science 62:184-191, 2012.

DOI:10.1016/j.corsci.2012.05.013.
[6] M. Mandel, L. Krüger. Determination of pitting sensitivity of the aluminium alloy EN AW-6060-T6 in a carbon-fibre reinforced plastic/aluminium rivet joint by finite element simulation of the galvanic corrosion process. Corrosion Science 73:172-180, 2013. DOI:10.1016/j.corsci.2013.03.033

[7] Y. Chenga, Z. Zhanga, F. Caoa, et al. A study of the corrosion of aluminum alloy 2024-T3 under thin electrolyte layers. Corrosion Science 46(7):1649-1667, 2004. DOI:10.1016/s0010-938x(03)00276-2

[8] F. Thébaulta, B. Vuillemina, R. Oltraa, et al. Modeling bimetallic corrosion under thin electrolyte films. Corrosion Science 53(1):201-207, 2011. DOI: $10.1016 /$ j.corsci.2010.09.010

[9] K. Xiao, C. F. Dong, H.Luo, et al. Investigation on the electrochemical behaviour of copper under $\mathrm{HSO}_{3}$-containing thin electrolyte layers. Int $J$ Electrochem Sci 7(8):7503-7515, 2012.

[10] S. Palani, T. Hack, A. Peratta, et al. Modeling approach for galvanic corrosion protection of multimaterial aircraft structures. [2015-01-28], http://www. beasy.com/news/pdfs/Aircraft_ Structure_Corrosion_DOD_2011.pdf

[11] L. Bortels, A. Rose. Computational galvanic corrosion prediction. [2015-05-25], http://www. asetsdefense.org/documents/ Workshops/SustainableSurfaceEngineering2011/ 4-Bortels $\% 20-\% 20$ Computational $\% 20$ Galvanic $\%$ 20Corrosion $\% 20$ Prediction $\% 20-\% 20$ inal.pdf.

[12] F. Corvoa, T. Pérez, Y. Martinc, et al. Time of wetness in tropical climate: Considerations on the estimation of TOW according to ISO 9223 standard. Corrosion Science 50(1):206-219, 2008. DOI:10.1016/j.corsci.2007.06.012

[13] H. Katayama, K. Noda, M. Yamamoto, T. Kodama. Relationship between corrosion rate of carbon steel and water film thickness under thin layer of artificial sea water. J Japan Inst Metals 65(4):298-302, 2001.

[14] D. A. Jones. Principles and prevention of corrosion. Prentice-Hall, Inc., Upper Saddle River, NJ, 1996. 